\title{
A ordem do discurso psiquiátrico: saber, poder, verdade e produção de exclusão social
}

\author{
The psychiatric discourse order: knowledge, power and social exclusion \\ production
}

Ana Paula Pimentel; Paulo Duarte de Carvalho Amarante

Escola Nacional de Saúde Pública Sergio Arouca, Fundação Oswaldo Cruz

\begin{abstract}
RESUMO:
O objetivo deste texto é apresentar uma sucinta reflexão sobre três acontecimentos identificados como formas históricas de exclusão da loucura (o desterro, o internamento e a objetivação da loucura como doença mental) em diálogo com as discussões apresentadas na aula inaugural proferida por Michel Foucault no Collège de France em 1970, convertida no livro A ordem do discurso ([1970] 2014). Nesse sentido, associaremos as formas históricas de exclusão aos sistemas externos de restrição do discurso elencados no livro-aula: a interdição, a oposição entre razão e loucura e a vontade de verdade. Examinaremos a maneira como estes sistemas criaram condições de possibilidade para as exclusões históricas e manutenção do sofrimento mental no lugar de objeto do discurso psiquiátrico.
\end{abstract}

Palavras-chave: psiquiatria; discurso; exclusão social

\begin{abstract}
:
This paper presents a brief reflection about three events identified as historical forms of exclusion of the madness (banishment, internment and the objectification of madness as mental illness) in dialogue with the discussions presented in the inaugural lecture given by Michel Foucault at Collège de France in 1970, converted into the book The Order of Discourse ([1970] 2014). In this sense, we will associate the historical forms of exclusion with the external systems of discourse restriction listed in the book: interdiction, the opposition between reason and madness and the will to truth. We will examine the way in which these systems created conditions of possibility of historical exclusions and maintenance of mental suffering as an object of psychiatric discourse.
\end{abstract}

Key-words: psychiatry; discourse; social exclusion

DOI:10.12957/mnemosine.2021.62178

A exclusão social da loucura é uma realidade largamente tematizada, questionada e combatida - especialmente a partir do processo de Reforma Psiquiátrica. No que tange ao contexto brasileiro isto vem ocorrendo desde o final da década de 1970. No entanto, superar este problema ainda é um difícil desafio para o campo da saúde mental; e, de fato, formas de exclusão e negativas de existência social (e até mesmo de existência humana) continuam insurgindo por efeito da rejeição da singularidade de quem sofre mentalmente. 
A noção de exclusão social pode ser vista como um verdadeiro 'guarda-chuva' conceitual, por abrigar variada produção teórica de diferentes campos de saber, pela diversidade de aplicação, de linhas argumentativas e de definições que continua suscitando. Na perspectiva que adotamos, a noção alude aos processos que sentenciam aqueles rotulados como loucos à retirada da vida social e, assim, à perda do direito à cidade, à participação social, à cidadania e ao exercício de liberdade (AMARANTE e TORRE, 2018). Trata-se de processos que vulnerabilizam, fragilizam ou provocam o corte dos laços sociais em diversas dimensões da vida, levando o sujeito a ter um lugar social negativo que o impossibilita de ter acesso dos direitos fundamentais (ESCOREL, 1999).

Embora Michel Foucault não tenha submetido a noção de exclusão social a uma elaboração temática, ele foi um dos pioneiros a pensar com profundidade analítica sobre a sistemática da exclusão social do louco, dedicando grande parte do seu fôlego investigativo a essa reflexão. Sob a luz da análise histórica, a partir de suas narrativas especialmente na obra História da Loucura na idade clássica (FOUCAULT, [1961] 2009) -, as tramas de saber-poder ganham contorno e desvelam, nos acontecimentos, as tecnologias de exclusão que reservaram para a loucura e sua singularidade o não-lugar, a segregação e o silenciamento. Na obra, três acontecimentos podem ser identificados como formas históricas de exclusão do louco: o desterro, o internamento e a objetivação da loucura como doença mental. Os dois primeiros acontecimentos criam condições de possibilidade materiais e discursivas para o terceiro.

Não é nossa pretensão colocar a noção de exclusão social em análise. Neste texto, evocamos a noção para enfatizar a dinâmica de tecnologias que engendrou o fenômeno da exclusão do louco. Nesse sentido, sublinhamos dois grandes aportes de Foucault, dois redirecionamentos teórico-metodológicos que sua abordagem permite no modo de investigar o problema em análise. O primeiro redirecionamento, conforme pode ser apreendido nas páginas de Microfísica do poder ([1979] 2014), consiste no movimento de buscar entender uma questão (do presente) 'olhando para trás', examinando a trama histórica, para distinguir os acontecimentos componentes da trama entre si, suas engrenagens e modos de ligação, os mecanismos estratégicos de produção e sustentação, seus efeitos e suas relações com o poder.

O segundo redirecionamento teórico-metodológico refere-se à retirada do foco de análise do sujeito excluído e enfoque na sociedade que exclui. Desse modo, ao invés de 
localizar o problema no sujeito (pensando em termos instituídos, como desvio da norma ou déficit do indivíduo), Foucault questiona a sociedade, questiona os processos sociais geradores do fenômeno da exclusão, utilizando o próprio fenômeno como um elemento analisador do funcionamento social, em face da maneira de perceber e produzir verdades sobre a loucura. Isso fica nítido em um dos pressupostos que entendemos ter sido assumido por ele (FOUCAULT, [1961] 2009): que a exclusão social da loucura seguiu em produção e reprodução nas malhas do espaço-tempo como desdobramento das respostas sociais ${ }^{1}$ adotadas diante do dilema representado pela loucura. Assim, a análise recai sobre os dispositivos discursivos (de saber e de poder) produtores de práticas concretas, com efeito de verdade, que conduzem à exclusão.

Foucault desenvolveu um recurso metodológico composto de quatro princípios que se dividem em dois conjuntos: o conjunto crítico e o conjunto genealógico. Por meio do conjunto crítico, ele realizou um grupo de análises para investigar os sistemas de exclusão da loucura e suas funções. Conforme explica, aplicando o princípio da inversão, o conjunto crítico tem o objetivo de “[...] cercar as formas de exclusão, [...] mostrar como se formaram, para responder a que necessidades, como se modificaram e se deslocaram, que força exerceram efetivamente, em que medida foram contornadas" (FOUCAULT, [1970] 2014: 57).

O conjunto genealógico, por sua vez, estuda a formação do discurso e aplica três princípios: da descontinuidade, da especificidade e da exterioridade. Este conjunto busca auxiliar na descrição das circunstâncias que ocasionaram a criação de objetos históricos e os preservaram em estruturas sociais. Por meio desse recurso, Foucault realizou análises guiadas a responder como as formas de exclusão se relacionaram com os sistemas de coerção e séries de discursos, identificando a que normas estas séries se ligavam, e em que condições surgiram e se desenvolveram.

Foucault ([1970] 2014) esclarece que os conjuntos de princípios (crítico e genealógico) não se aplicam totalmente em separado e que ambos os tipos de análise, inclusive, devem se apoiar e complementar. O livro A História da Loucura na idade clássica ([1961] 2009) é a materialização desse esforço metodológico crítico-genealógico - o que fica evidente quando o relemos orientados pelas elaborações presentes em $A$ ordem do discurso ([1970] 2014). Posto isto, a partir deste ponto as reflexões se darão no sentido de revisitar e sintetizar os acontecimentos identificados como formas históricas de exclusão da loucura, à luz das contribuições sistematizadas no livro-aula. 


\section{Exclusão por desterro e por internamento - ritual, interdição e oposição entre razão e loucura}

É possível encontrar registros sobre a temática do desterro em, basicamente, todos os períodos da história humana. Logo, o afastamento compulsório de uma pessoa da sua cidade ou país é um tema presente e importante em qualquer época. As formas de execução do afastamento e motivos para a prática são muito variadas; e ser classificado como louco foi um desses motivos - uma das situações que engendrou o que podemos avaliar como a primeira forma histórica de exclusão social do louco.

Reportemo-nos à narrativa da História da Loucura na idade clássica ([1961] 2009), que começa na passagem da Idade Média para a Idade Moderna. Este recorte temporal circunscreve o momento em que a loucura deixa gradualmente de ser vista da forma diversificada, o que acontecia até então na cultura ocidental, a partir da tradição trágica ${ }^{2}$, e começa a ser marcada de forma simbólica na esteira da tradição crítica até se tornar depositária do temor e consequências similares àquelas que a lepra acarretava (estigma e banimento). Os casos de lepra foram desaparecendo, mas os valores e as imagens fixadas à figura do leproso, bem como a estrutura da exclusão destinada a ele permaneceram durante um longo tempo à frente, reorientadas para o seu novo herdeiro: o louco (FOUCAULT, [1961] 2009: 06).

No final da idade média, considerava-se louco quem perturbava a ordem social com determinados comportamentos ${ }^{3}$ incomodativos e causadores de insegurança na comunidade. Em resposta a essa questão, certas cidades europeias livravam-se do louco despachando-o em navios (as Naus dos Loucos) ${ }^{4}$ para os chamados 'lugares de peregrinação' - cidades onde o sujeito rejeitado permanecia errante, mantido longe da sociedade que não tolerava a sua presença - ou para lugares de contraperegrinação: regiões que não eram tipicamente de peregrinação, mas recebiam e aprisionavam os loucos em cárceres subvencionados localmente. Portanto, o louco era desterrado, ou seja, expurgado ${ }^{5}$ através do rito da nau para alívio da sociedade, que desejava dele se separar e se desresponsabilizar. É essencial prestar atenção nos elementos imagéticos apresentados nesse acontecimento: a imensidão do mar, o navio conduzindo sua "carga insana" para longe em deslocamento lento através das águas, tornando-se uma silhueta desvanecida a sumir no horizonte. Esses elementos visuais presentes no rito da nau, conforme Foucault assinala, forneciam imagens que davam as garantias do destino de errância, de incertezas, de 'passageiro eterno' para o louco. 
Outra forma de desterro sofrida pelo sujeito classificado como insano à época era o escorraçamento para fora das cidades através de açoitamentos e bastonadas. Tratava-se de um ritual marcado por forte carga simbólica, com punições públicas exercidas durante jogos simulados de perseguição (FOUCAULT, [1961] 2009: 11). No contexto em questão, muitas cidades eram isoladas por muros que lhes serviam de proteção contra invasões. Por conseguinte, o muro era uma figura central e sólida, que cumpria a função de delimitar áreas, de demarcar lados (o dentro e o fora), de promover a organização estrutural geográfica e estratégica para defesa do território.

Ademais, no acontecimento em foco, o muro cumpre nova função: permitir o exercício do controle social, separando quem está incluído como cidadão ou não, quem pertence à cidade ou não. Assim, a função ordinária dos muros é incluir-proteger ou excluir-barrar; e, nesse processo, o louco era classificado como o não-cidadão, expatriável, e seu destino é o lado de fora. No exterior da cidade, abandonado à própria sorte, precisará lutar solitariamente pela vida em meio ao ambiente desconhecido, desprotegido, provavelmente bastante hostil e perigoso, em que era descartado.

Um pouco mais adiante tem início um período cuja principal marca é a valorização da razão. Assim, pela ótica do Iluminismo, os sujeitos eram classificados em duas categorias: os que detinham a razão e os desprovidos desta. Desse modo, entra em exercício uma concepção sobre a loucura cuja base é a lógica cartesiana binária, sendo a desrazão o novo critério definidor da experiência da loucura. Logo, esta lógica principia um modo de exclusão que rotula e rejeita as pessoas identificadas como desarrazoadas. Sobre isso, Porter (1991) observa que a intenção naquele contexto era afastar e aniquilar tudo quanto fosse julgado irracional.

Então, se na prática do desterro o louco era expulso da cidade (por via marítima ou por terra), pela oposição entre loucura e razão ele estava fadado a um novo dispositivo de segregação, porém no interior da cidade: o hospital geral. Este acontecimento, que ocorreu da Era Clássica até o final da Idade Moderna, é discutido principalmente em dois textos foucaultianos - A Grande Internação ([1961] 2009) e O Nascimento do Hospital ([1979] 2014).

No período em questão, o hospital cumpria função semelhante à de um depósito, onde jaziam pessoas marginalizadas pela sociedade - preferencialmente os pobres e miseráveis, mas também os hereges, idosos, os portadores de doenças contagiosas e outras enfermidades em geral, os delinquentes, as prostitutas, entre outros. Os loucos estavam entre o público elegível e, inclusive, eram considerados a parcela perigosa do 
grupo de internados, sendo por isso mantidos presos por correntes (AMARANTE, 2008). Esse cenário, por si só, seria suficiente para transmitir uma mensagem: a de que os loucos deveriam ser objeto de exclusão e preocupação.

Evidentemente, o hospital geral não era uma instituição de cuidado, mas uma espécie de 'morredouro', isto é, um lugar produtor de desfechos letais (FOUCAULT, [1979] 2014: 175). Ocupando o lugar de 'instância da ordem', e servindo aos interesses eclesiásticos, monárquicos e burgueses, os usos do hospital refletiam a percepção da diferença como desvio, falha moral ou erro da razão e, por isso, uma ameaça aos princípios de ordem, progresso e racionalidade.

É esclarecedor olhar os acontecimentos de exclusão por desterro e por internamento em sua essência ritualista. Rituais possuem natureza simbólica, ou seja, são composições de signos que constituem um tipo de linguagem e apontam uma realidade externa a eles. Podem ser entendidos como recursos para modelagem das percepções humanas ou, em outras palavras, são instrumentos criadores de realidades sociais. Nos acontecimentos em análise, vemos que os signos cumprem a função de providenciar nebulosos lembretes que não se referem ao que é lembrado estritamente; são lembretes que incluem não somente o que foi visto, mas também tudo o que a consciência pode abraçar (visível e invisível) na realidade imaginária guiada pela lógica discursiva ativa nos domínios da imagem. Desse modo, podemos compreender os rituais de desterro (o ritual das "Naus dos Loucos" e os rituais de expulsão extramuros da cidade) e o internamento em hospital geral como acontecimentos eficazes em conectar a palavra à coisa, o discurso à imagem.

Em suas narrativas figuradas (utilizando recursos pictóricos, gestuais, geográficos e espaciais), os rituais de desterro e o internamento lograram produzir significações sobre o louco apelando ao sentido da visão - que é mais próximo da linguagem e viabiliza a criação de vasta rede de significações em um repertório discursivo. Machado (2006) observa que a análise de Foucault sobre a loucura nos períodos destacados até este ponto é sintética e privilegia as expressões pictóricas e linguísticas com o claro propósito de evidenciar o início do processo em que a razão, com base no critério da verdade e da moral, busca dominar e excluir a loucura (MACHADO, 2006: 43).

Para Foucault ([1970] 2014), os sistemas externos de restrição do discurso equivalem a sistemas de poder, que operam o controle, seleção, organização e redistribuição do discurso nas sociedades. Ele situa os rituais como os mais externos e 
visíveis desses sistemas, classificando-os como práticas que determinam lugares, papéis, atores e indicam quais signos e de que modo farão a composição dos discursos. A interdição é apontada como o mais familiar e notório sistema externo de restrição, podendo se combinar de três modos em esquemas de reforço e compensação: i) tabu do objeto - restrição relativa ao que se pode dizer; ii) ritual de circunstância - restrição relativa ao momento em que se pode dizer; e iii) direito exclusivo ou privilegiado de quem fala - restrição relativa a quem pode dizer.

O desterro, primeira forma histórica de exclusão, interditava radical e concretamente a existência social do louco. A partir dele, o princípio da interdição operava de forma plena sobre a palavra do louco, e sutilmente guiava o que o corpo social poderia (ou deveria) dizer e pensar a respeito da loucura. $\mathrm{O}$ internamento é a segunda forma histórica de exclusão do louco e foi suportado pelo segundo sistema de restrição do discurso destacado por Foucault ([1970] 2014): a oposição entre loucura e razão. Tratava-se de um sistema que agia identificando os signos de insanidade na palavra do louco que, por esse motivo, nunca era passível de acolhimento ou escuta, sendo sempre separada, rejeitada e condenada ao descrédito.

Com efeito, os signos, especialmente os imagéticos, cooperaram para fixar nas consciências (medieval e moderna) a percepção da loucura como uma diferença estrangeira, radicalmente alheia, perigosa, defeituosa, desregrada e irracional. Nesse sentido, os rituais foram eficazes ao desempenhar uma função de dupla-face: promoção de determinados discursos e restrição de outros. Assim, o período de transição entre a Idade Média e a Idade Moderna registra o percurso da construção de uma consciência crítica sobre a experiência da loucura, em que ela será tomada cada vez mais pelo viés negativo. Isso criou um contexto fértil para a terceira grande forma de exclusão social do louco, tema que passamos a discutir em seguida.

\section{A ordem psiquiátrica - doença mental e a vontade de verdade}

As muitas mudanças da Idade Média ao início da Idade Moderna trouxeram à luz a ciência moderna e lançaram os alicerces do método científico, levando os diferentes campos de saber ao empenho em estruturar suas ideias cientificamente, a realizar alianças ideológicas e ajustamentos com o discurso hegemônico para facilitar a aceitação das suas proposições. No findar do século XVIII, diante de condições de possibilidade, começa a operar uma nova racionalidade que culminará na reificação da loucura como doença mental, constituindo a terceira e durável forma de exclusão social do louco. Este é o 
contexto em que a desrazão perde lugar para a alienação, que passa a ser o critério de distinção do louco na ordem social (AMARANTE, 2009). Assim, nasce a clínica psiquiátrica - que subordina o campo da loucura à medicina, transformando-o no campo da doença mental.

Este marco histórico costuma ser associado ao lançamento do livro bicentenário de autoria do médico francês Phillipe Pinel, o Tratado Médico-Filosófico sobre a Alienação Mental ou a Mania ([1801] 1988), considerado a obra inaugural da ciência psiquiátrica. Ele traz o registro do dispositivo de tratamento batizado como Tratamento Moral, cujo objeto é a alienação mental - novo nome atribuído à experiência da loucura, que passa, assim, a ter status de doença.

Entre as variadas concepções de doença predominantes até o fim do século XVIII, embora houvesse divergências, a noção de doença remetia a uma espécie de "entidade independente" que acomete as pessoas e pode ser agrupada em classes, gêneros e espécies (HEGENBERG, 1998). Afinado com esse pensamento, o tratado pineliano sistematiza um modelo de pensamento-intervenção sobre o psíquico e traz orientações para catalogar e descrever as manifestações da loucura (ou seja, os sintomas), atribuindo-lhes esclarecimentos "científicos" de acordo com o modelo biomédico da História Natural ${ }^{6}$, conformando um paradigma que padroniza a compreensão do psíquico por comparação com o biológico.

O livro é o testemunho de que a primeira especialidade médica, a psiquiatria, estava harmonizada com as ideias da época - contexto histórico em que o discurso reconhecido e apreciado (o discurso biomédico) é aquele ao qual se atribui o valor de verdade. Nessa direção, a nova ciência mental apresentava um discurso naturalista e conveniente, pois se adequava muito bem à abordagem de problemas locais diversos (tais como jurídicos, morais e econômicos); além do que, seu discurso estava guarnecido de cientificidade, conformado à disciplina médica, que estava "no verdadeiro" da ciência moderna.

Ocorria ainda que o tratamento moral era fundamentado na percepção de que os sujeitos deveriam ser assistidos em instituições fechadas, onde teria que ser aplicada a disciplina e a repressão para reconduzir à razão (PINEL, [1801] 1988). Assim, surgem os asilos de alienados: novo espaço de exclusão para a loucura, disfarçado de instituição médica, que mantém a função histórica de classificar, reprimir e segregar. 
Segundo Machado (2006), a psiquiatria buscava "desalienar" por meio da instauração de uma ordem moral, apresentando-se como prática terapêutica e moralmente educativa a um só tempo. Ele assevera que, ao estudar esse acontecimento, devemos ter em conta que o saber e o poder estão mutuamente implicados, não havendo relação de poder divorciada da constituição de um campo de saber, e que os saberes criam novas relações de poder (MACHADO, 2006).

Podemos analisar o nascimento da disciplina alienista sob o entendimento da noção de vontade de verdade - terceiro sistema externo de restrição do discurso definido por Foucault ([1970] 2014) que, conforme explica, funciona realizando a distinção entre verdadeiro e falso, definindo o perfil de sujeito autorizado a dizer certas coisas sobre determinados tipos de objetos em dado momento, cujo discurso será aceito socialmente como discurso de verdade ${ }^{7}$. De fato, observamos que o discurso da alienação cumpre a função de legitimar o saber médico-psiquiátrico como verdade e institui o alienista como o sujeito de saber, com poder de dizer-fazer sobre a loucura.

Interessa observar que a ciência psiquiátrica teve sua identidade definida à medida que a diferença da loucura foi construída. Examinemos essa assertiva a partir do que Woodward (2000) diz a respeito dos sistemas sociais que definem identidades pela afirmação de diferença. A autora examina a ligação entre os mecanismos de produção de significações e de representação, e põe em relevo algumas características das identidades, dentre as quais escolhemos duas, implicadas na relação de saber-poder entre a psiquiatria e a loucura.

A primeira característica alude à natureza relacional da identidade, isto é, uma identidade geralmente depende de outra para existir, e conduz à formação do par identidade-diferença, estabelecendo a díade "nós x eles". Sobre esse tipo de oposição, releva salientar que criar identidade passa pela ação de afirmar a igualdade dentro do conjunto identitário. Nessa direção, a análise da história da loucura revela que a identidade da psiquiatria (o "nós") foi firmada pelo enquadre da loucura (o "eles") - uma forma subjetiva complexa, singular e heterogênea - em uma categoria simplificada, objetiva e negativa: a doença mental.

A segunda característica é complementar à primeira e se refere ao fato de que identidades se diferenciam por meio de marcação simbólica, “[...] meio pelo qual damos sentido para as práticas e as relações sociais, definindo, por exemplo, quem é excluído e quem é incluído" (WOODWARD, 2000: 14). Sobre isso, Amarante e Freitas (2015) dizem que, na luta por validar a sua identidade científica, a psiquiatria exerceu uma 
espécie de "abuso da razão", condenando a loucura à negatividade absoluta ao atribuir a ela um conjunto diversificado de signos depreciadores, relidos e apresentados como sintomas da doença mental (AMARANTE e FREITAS, 2015).

Outro ponto a frisar é o fato de que a lógica da exclusão, conforme ressaltado por Scarcelli (2011), se ampara na lógica de classe. A lógica de classe estabelece critérios e, com base neles, organiza a formação de grupos de iguais (classe que pertence) e grupos de diferentes (classe que não pertence). A autora ressalta que o problema não está na classificação em si, visto que ela é uma condição de pensamento. Segundo assevera, o problema está no uso político dessa lógica, pois as representações daí provenientes podem gerar estigmas, segregar e alienar. E, decerto, as exclusões históricas cumpriram a função de transmitir um discurso classificatório sobre o louco, contrapondo ordem-desordem, moral-imoral e razão-loucura, normal-patológico para realizar a separação pertence/não pertence.

Nessa medida, a partir da objetivação da loucura como doença mental, as relações estabelecidas com o louco passam a ser mediadas por signos de negatividade (os sintomas). Uma das consequências disso é a tendência da sociedade a assimilar o discurso psiquiátrico como verdade inquestionável, passando a apresentar para com o louco a mesma conduta estigmatizante e silenciadora produzida e adotada pela psiquiatria (AMARANTE, 2008). Tal consequência pode ser considerada como um dos principais mecanismos de manutenção da exclusão social, pois fabrica uma realidade em que a loucura estigmatizada pela diferença é impedida de adentrar o conjunto mais amplo dos "iguais" - que, nessa lógica, passa a ser composto apenas por aqueles que se enquadram nos padrões normativos de igualdade em termos de condições e características mentais (os não-loucos).

É preciso olhar de forma mais crítica para essa realidade e pautar que ela é representativa de uma situação crônica de violação de direitos humanos e massacre, entre outros, do direito constitucional à igualdade (direito fundamental que assevera sermos todos iguais perante a lei, sustentador da noção de cidadania), dado que impede pessoas de usufruírem verdadeiramente da condição cidadã. Dessa perspectiva, não é difícil concluir que a moralidade psiquiátrica cria desigualdades, pois dificulta o acesso, mediante a atribuição do rótulo da "doença mental", a determinados direitos, oportunidades e experiências sociais, tal como encontrar espaço no mercado de trabalho, no sistema educacional, nas redes e dispositivos sociais em geral. E, ainda, alimenta a 
desigualdade existencial, responsável pela restrição da liberdade de agir, circular, e pela negativa de (igual) reconhecimento e respeito.

Therborn (2010) nos ajuda a refletir a respeito do desdobramento das questões suprarreferidas. Segundo seus apontamentos, igualdade pode ser compreendida como antônimo de diferença (como na concepção matemática desta noção), no caso da diferença ser tomada como justificativa de dispensação de tratamento diferente e necessário para as pessoas. Mas, também pode ser antônimo de desigualdade quando há violação de uma norma moral social de igualdade. Nessa direção, desigualdades são diferenças hierárquicas passíveis de serem evitadas, e não justificáveis moralmente. Em suma, desigualdades podem ser produzidas por distintos dispositivos, como a exclusão, por exemplo.

Interessante mencionar a crítica de Robert Castel (1998) em sua mirada genealógica sobre a sociedade salarial, onde assinala que não é possível uma situação de total exclusão da sociedade. Por isso, no lugar da noção de exclusão, ele sugere a noção de 'desfiliação', que diz respeito ao enfraquecimento dos vínculos com as estruturas sociais, à dissolução das redes de sociabilidade em consequência do processo de vulnerabilização dos sujeitos - que não são totalmente desligados da sociedade; embora estejam às margens de algumas esferas sociais, permanecem dependentes do núcleo. Além do mais, os sujeitos são incluídos em determinadas esferas que produzem existência social segundo determinados jogos de poder e interesses. Um bom exemplo está nas consequências dos fenômenos da patologização e medicalização do sofrimento mental: a tecitura de uma rede mercadológica lucrativa e ávida pela clientela de "doentes mentais" (produzida e alçada à categoria de consumidora), com vasta oferta de pseudosoluções psicofarmacológicas e de serviços médicos.

\section{Considerações finais}

Para Foucault ([1970] 2014), o discurso está estreitamente relacionado com o desejo e o poder; ele não apenas evidencia as lutas ou dispositivos de dominação, mas é ele mesmo o objeto pelo qual a luta acontece, bem como o poder que se quer obter. Tal tese se confirma na observação da maneira como vem acontecendo historicamente a reificação de saberes em práticas, sempre em consonância com o tipo de vontade de verdade vigente em cada época. Isso cria condições para que determinados grupos ajam, segundo a receptividade do contexto, e logrem atingir seus intentos pela linguagem - o que comprova a potência do discurso na produção de realidades. 
No que se refere à construção da diferença da loucura, os acontecimentos das exclusões históricas expõem como, sob quais condições e para que desígnios diversos signos pejorativos identificatórios de diferença foram impingidos ao sujeito considerado louco ao longo do espaço-tempo, fortificando a experiência crítica. Dispositivos disciplinares e biopolíticos consolidaram uma identidade social negativa para o louco, com base naquilo que, nele, falava de sua diferença. Assim, os sistemas de interdição, de oposição entre razão e loucura e de vontade de verdade foram sustentáculos discursivos eficazes em desenhar a imagem do louco como estrangeiro, como elemento nãopertencente e anormal, designando para ele o destino condizente com a forma de percebêlo.

Com efeito, a psiquiatria despontou como nova especialidade médica apoiada em um discurso categorizador e normatizador para transformar a loucura em doença mental; e, apesar da sua fragilidade científica, teórica e prática, conquistou reconhecimento como autoridade para dizer quem é normal e quem é anormal, ou não semelhante. Isso teve suporte no sistema de restrição de discurso que se apoia em práticas institucionais: a vontade de verdade. Esse é o sistema que efetua a divisão historicamente construída entre verdadeiro e falso, validando alguns discursos como verdadeiros e invalidando outros como falsos. A dinâmica de oposição entre o verdadeiro e o falso seguiu definindo a vontade de verdade ocidental, que assumiu diferentes formas no decurso do tempo, geralmente fazendo supor que as transformações da ciência se desdobram unicamente de avanços e descobertas, e não da emergência de novos tipos de vontade de verdade ligados ao valor-poder dos discursos produzidos.

Está fora de dúvida que, sob o signo de discurso verdadeiro, a vontade de verdade psiquiátrica figura, na atualidade, como se sua história estivesse dissociada da história das verdades que contingenciam, punem, silenciam, adoecem e excluem. Esta realidade delineia diversas transformações da sociedade contemporânea, com destaque para o encapsulamento da loucura no registro exclusivamente biomédico, o que obstaculiza outras histórias e olhares para a questão, que considerem as dinâmicas relacionais, políticas, econômicas e subjetivas na produção social do sofrimento psíquico.

Obviamente, existem muitas diferenças entre os seres humanos (diferenças de etnia, gênero, religião, condição mental, orientação sexual, e muito mais). Mas, o uso de quaisquer diferenças para a sustentação de desigualdades e, consequentemente, exclusão deve ser repudiado e combatido. Nesse sentido, na produção de uma saúde mental crítica, 
é significativo não prescindir de problematizar as relações de poder, o direito à singularidade e o direito à igualdade de maneira correlacionada. Certamente, as reflexões daí advindas serão profícuas para o planejamento multidisciplinar de Políticas públicas do campo que, de fato, viabilizem a inclusão social. Entendemos que estas são condições importantes para enfrentar as desigualdades que afligem as pessoas em sofrimento psíquico e promover saúde com integralidade.

\section{Referências}

AMARANTE, Paulo Duarte de Carvalho. O homem e a serpente. Outras histórias para a loucura e a psiquiatria. Rio de Janeiro: Fiocruz [1. ${ }^{\text {a }}$ ed.] 2008.

. Loucos pela vida: a trajetória da reforma psiquiátrica pelo Brasil. $2^{\mathrm{a}}$ ed. $4^{\mathrm{a}}$ Reimpressão. Rio de Janeiro: Editora Fiocruz, 2009.

; FREITAS, Fernando. Foucault e Basaglia: um debate sobre a razão (outra). Em: RODRIGUES, Heliana de Barros Conde; PORTOCARRERO, Vera; VEIGANETO, Alfredo (organizadores). Michel Foucault e os saberes do homem: como, na orla do mar, um rosto de areia. Curitiba: Prismas, 2015

; TORRE, Eduardo Henrique Guimarães. "De volta à cidade, sr. cidadão!” reforma psiquiátrica e participação social: do isolamento institucional ao movimento antimanicomial. Rev. Adm. Pública, Rio de Janeiro, v. 52, n. 6, p. 1090-1107, dez. $2018 . \quad$ Disponível em <http://www.scielo.br/scielo.php?script=sci_artex t\&pid=S0034$76122018000601090 \& \operatorname{lng}=$ pt\&nrm=iso>. Acesso em 05 jan. 2020.

BRANDÃO, Junito de Souza. Mitologia Grega. Vol. III. Petrópolis: Vozes, 1987.

CASTEL, Robert. As Metamorfoses da Questão Social: Uma Crônica do Salário. [Tradução de Iraci D. Poleti]. Rio de Janeiro: Editora Vozes Ltda. 1998.

ESCOREL, Sarah. Vidas ao léu: trajetórias de exclusão social. Rio de Janeiro: Fiocruz, 1999.

FOUCAULT, Michel (1961). História da loucura na Idade Clássica / Michel Foucault; [Tradução José Teixeira Coelho Neto]. 8. ed. São Paulo: Perspectiva, 2009.

(1970). A Ordem do Discurso: aula inaugural no Collège de France, pronunciada em 2 de dezembro de 1970 / Michel Foucault; [Tradução Laura Fraga de Almeida Sampaio]. 24. ed. São Paulo: Edições Loyola, 2014.

(1979). Microfísica do Poder / Michel Foucault; [Organização, introdução e revisão técnica de Roberto Machado]. 28. ed. Rio de Janeiro: Paz e Terra, 2014.

HEGENBERG, Leonidas. Doença: um estudo filosófico. Rio de Janeiro: Editora Fiocruz, 1998.

MACHADO, Roberto. Foucault, a Ciência e o Saber. Rio de Janeiro: Zahar, 2006.

PINEL, Philippe (1801). Tratado médico-filosófico de la enajenación mental o mania / Philippe PINEL; Tradução de Luís Guarneria y Allavena - Madrid: Ediciones Nieva, 1988. 
PORTER, R. Uma História Social da Loucura. Trad. Angela Melim. 2.ed. Rio de Janeiro: Zahar, 1991.

SCARCELLI, Ianni Regia. Entre o hospicio e a cidade: dilemas no campo da saúde mental. São Paulo: Zagodoni Editora, 2011.

THERBORN, Göran. Os campos de extermínio da desigualdade. Novos estud. CEBRAP, São Paulo, n. 87, p. 145-156, jul. 2010. Disponível em: http://dx.doi.org/10.1590/S0101-33002010000200009. Acesso em 16 jul. 2020.

WOODWARD, Kathryn. Identidade e diferença: uma introdução teórica e conceitual. Em: SILVA, Tomaz Tadeu (organizador). Identidade e diferença: a perspectiva dos estudos culturais. Petrópolis: Vozes, 2000.

\author{
Ana Paula Pimentel \\ Doutoranda no Programa de Pós-Graduação em Saúde Pública da ENSP/FIOCRUZ \\ (Bolsa CNPq) \\ E-mail:paulinha_pimentel@yahoo.com.br \\ Paulo Amarante \\ Pesquisador titular do Laboratório de Estudos e Pesquisas em Saúde Mental \\ (LAPS/ENSP/FIOCRUZ) \\ E-mail: pauloamarante@gmail.com
}

\footnotetext{
${ }^{1}$ Respostas ordinariamente mobilizadas por afetos de estranhamento, intolerância e recusa da diferença que ela expressa, associados ao desejo de controle e normalização.

${ }^{2}$ Em Foucault ([1961] 2009), a experiência trágica é definida como aquela em que a loucura podia ser percebida em termos diversos, como algo da ordem do saber ou da verdade, do artístico, do mágico ou do sagrado, dos vícios, do burlesco ou do ridículo, entre outras associações, abrangendo experiências positivas. Em contraposição, a experiência crítica é aquela que vai gradualmente restringindo as associações possíveis, provocando o olhar para a loucura somente a partir de vieses negativos.

${ }^{3}$ Como, por exemplo, cometer delitos, andar nu pelas ruas ou circular pela cidade (o que caracterizava 'estado de vagabundagem').

${ }^{4} \mathrm{O}$ tema da nau era recorrente na literatura de ficção renascentista, com inspiração oriunda da mitologia grega, em referência à lendária Argo - embarcação que levou seus tripulantes (os argonautas) em uma jornada heroica de muitas escalas e desafios (BRANDÃO, 1987). Muitas composições foram inspiradas nas naus, mas a Nau dos Loucos (a Narrenschiff de Brant - 1497) foi a única que existiu de fato (FOUCAULT, [1961] 2009).
}

5 A palavra expurgo retrata perfeitamente o objetivo do rito em análise. Na língua portuguesa, algumas significações desta palavra são: purgar completamente, livrar do que é nocivo ou imoral, limpar; purificar - sentidos que bem podem representar a realidade em questão.

${ }^{6}$ Trata-se de uma racionalidade que entende a doença como resultante de alterações orgânicas, expressa como conjunto de sintomas e sinais. Entende que os sintomas e sinais seguem um padrão e precisam ser explicados e categorizados para que, assim, seja possível diferenciar os tipos de doenças mentais entre si (MACHADO, 2006; AMARANTE, 2015).

${ }^{7} \mathrm{O}$ discurso de verdade não precisa ser necessariamente verdadeiro, mas é aceitável e recebido como verdade porque atende a certas exigências, é direcionado a um objeto específico e é aberto a novas formulações, a acréscimos que lhe dão sustentação e condições de reprodução - conforme critérios de cientificidade da ciência moderna. 